\title{
Study of the Determinant Factors in Seizure Following Gastroenteritis in Children Admitted in Aswan University Hospital
}

\author{
Hanan Mohammed Abd El-Moneim, Mohamed Baha Eldeen El Amer, Nilly Abdelmoti Abo Baker* \\ Department of Pediatrics, Faculty of Medicine - Aswan University, Egypt \\ *Corresponding author: Nilly Abdelmoti Abo Baker, Mobile: (+20) 1111568634, E-Mail: drnilly7@yahoo.com
}

\begin{abstract}
Background: Diarrhea is a leading cause of illness and death in children of developing countries, where an estimated 1300 million episodes and 3.2 million deaths occur in under-5 children. About $80 \%$ of deaths due to diarrhea occur in the first 2 years of life. Convulsions may occur during a diarrheic illness. Children may develop febrile seizures if fever accompanies the diarrhea.

Objective: The aim of the current work was to investigate the prevalence and determinant risk factors of seizure in children with gastroenteritis in children admitted to Aswan University Hospital in Egypt.

Patients and Methods: This prospective cross-sectional study included a total of 60 children having gastroenteritis and seizure, attending at Aswan University Hospital. This study was conducted between April 2019 to the end of September 2019.

Results: $46.7 \%$ of cases had mild fever, $61.7 \%$ of cases had gastroenteritis $>5$ days, vomiting frequency was $>3$ times per day in $73 \%$. Mean serum calcium was $5.55 \pm 0.614 \mathrm{mg} / \mathrm{dl}$, mean potassium was $4.72 \pm 0.632 \mathrm{mmol} / \mathrm{L}$, mean sodium was $135.67 \pm 5.82 \mathrm{mmol} / \mathrm{L}$ and mean $\mathrm{PH}$ was $7.36 \pm 0.694$. Acidosis and hyponatremia were the most frequent disorder among the patients. High grade fever, gastroenteritis $>5$ days and vomiting more than 3 times per day were significantly more frequent in patients with convulsion compared to non-convulsion patients.

Conclusion: Electrolyte impairment is fairly common in children with acute gastroenteritis. High grade fever, gastroenteritis for $>5$ days, vomiting $>3$ times per day, blood urea nitrogen, potassium and sodium found to be significant predictors of convulsion.
\end{abstract}

Keywords: Gastroenteritis, Diarrhea, Convulsions, Children.

\section{INTRODUCTION}

The term gastroenteritis denotes infections of the gastrointestinal tract caused by viral, bacterial, or parasitic pathogens. The most common symptoms are diarrhea and vomiting, which can be accompanied by fever and abdominal pain ${ }^{(1)}$. Diarrhea has a high contribution to the death of infants (9\%), which accounts for about $71 \%$ of deaths per year in the world (2). An average of 166 million deaths occurred in 2014 in infants below the age of 5 years old in developing countries, of them about $80 \%$ were in Africa, South Asia, and Middle East ${ }^{(3)}$.

Gastroenteritis can be found in healthy infants without any association with diseases such as meningitis, encephalitis, and encephalopathy (4). Gastroenteritis occurs mostly in the winter and early spring, and the most common cause for this is rotavirus (5).

In children, the daily water exchange rate is much higher than adults, as well as the incomplete renal development in children, which results in more extracellular fluid. Therefore, water and electrolyte disturbances in children are more dangerous than in adults ("). The most important complication of gastroenteritis in children is seizure, which is mostly caused by fever, electrolyte disturbances, meningitis and sometimes toxins ${ }^{(5)}$. Electrolyte disturbances such as hyponatremia, hypernatremia and hypocalcaemia are the major cause of seizures in these children ${ }^{(7)}$. However, in many cases, a seizure following gastroenteritis occurs without electrolyte disturbances and abnormalities in Electroencephalogram (EEG) ${ }^{(\boldsymbol{(})}$. In some cases, seizures following gastroenteritis occurs without fever which is not necessarily febrile seizure due to the gastroenteritis ${ }^{(9)}$.Various spectrums of benign convulsions or epileptic syndromes may develop in infants and pediatrics ${ }^{(\mathbf{1 0})}$.

Considering the high prevalence of gastroenteritis in children, the complications caused by this disease, which is involved in the morbidity and morbidity of the disease, especially the seizure following gastroenteritis, is very important. Vafaei $\boldsymbol{e} t$ al. (10) reported that electrolyte impairment is fairly common in children with acute gastroenteritis. Education about the management of children with seizure can be an important factor in this regard.

Khosroshahi et al. (11) said that benign convulsion with mild gastroenteritis is a distinct clinical entity that has not been categorized by the International League against Epilepsy. It is known as a situation-related seizure. It mostly happens in infants and has a favorable prognosis and neurologic evaluations usually turned out to be unnecessary. The exact path-physiology remains undetermined. Further prospective investigations needed to be performed in this entity. Increased awareness of pediatricians and pediatric neurologists of this newly recognized clinical disorder can lead to enhance case detection and avoid expensive and unnecessary neuro-diagnostic investigations. 
The aim of the current study was to investigate the prevalence and determinant risk factors of seizure in children with gastroenteritis in children admitted to Aswan university hospital in Egypt.

\section{SUBJECTS AND METHODS}

This prospective cross-sectional study included a total of 60 children having gastroenteritis and seizure, attending at Aswan University Hospital. This study was conducted between April 2019 to the end of September 2019.

Inclusion criteria: Patient age from 1 month - 6 years and all patients admitted to Aswan university hospital with diagnosis of gastroenteritis.

Exclusion criteria: Known history of chronic disease as Renal, endocrine, cardiac disease, known neurological abnormalities, and delayed psychomotor and patients diagnosed as epilepsy.

\section{All children included in this study were subjected to:}

Full history taking: Child sex, age, residency, consanguinity of parents, birth weight, natal, postnatal, developmental history, type of infant feeding (breast fed or formula fed), history of cow milk introduction before age of one year, vaccination history, history of upper respiratory tract infections. presenting symptoms. similar cases in the family, history of associated diseases. and history of hospital admission.

History of gastroenteritis: Diarrhea: ask about frequency, volume, consistency, odor, tenesmus, blood, mucus, abdominal pain, vomiting, urine output, weight loss, history of ingestion of unusual food and duration. Vomiting: ask about onset, frequency, headache, does vomiting comes through nose, projectile, Relationship to feeding, consistency of vomitus, undigested food, bile, blood, and history of drug ingestion.

History of Fever: Sudden or gradual onset, high or low grade, associated chills, sweating, convulsion, duration of fever, pattern (continuous, remittent, or intermittent).

History of Convulsion: Seizure characters (type of seizure, the number of seizures, the interval between the gastrointestinal symptoms and seizure, and number of cluster seizures) were collected from patients' medical reports that are generally filled by pediatric residents. Duration of seizures was recorded and analyzed. And information about the type of seizures was determined by direct observation of health-care providers (doctor/nurse), description of parents or both.

Full physical examination:

Complete physical examination head- to- toe: General examination, chest examination, cardiac examination, abdominal examination, neurological examination, genitourinary examination, skin examination and presence of congenital anomalies.

Investigation: The following were done for every patient after the attack of convulsion: CBC, CRP, serum glucose, total calcium, sodium, potassium, BUN, creatinine, ABG, AST, ALT.

Ethical approval and written informed consent: An approval of the study was obtained from Aswan University academic and ethical committee. Every patient signed an informed written consent for participation in the work.

\section{Statistical Analysis}

An Excel spreadsheet was established for the entry of data. We used validation checks on numerical variables and option-based data entry method for categorical variables to reduce potential errors. The analyses were carried with SPSS software (Statistical Package for the Social Sciences, version 24, SSPS Inc, Chicago, IL, USA). The normality of the data were assessed using Shapiro-Wilk Test. Numerical data were described as mean \pm SD if normally distributed; or median and interquartile range [IQR] if not normally distributed.

Frequency tables with percentages were used for categorical variables. Independent Student t-test and paired t-test were used to compare parametric quantitative variables; while Mann-Whitney tests and Wilcoxon matched pairs test were used to compare non-parametric quantitative variables. Chi-square test or McNemar-Bowker tests were used to analyze categorical variables. Multilinear logistic regression was undertaken to assess the predictors of mortality. A $\mathrm{p}$-value $<0.05$ is considered statistically significant. 


\section{RESULTS}

Table (1): Demographic distribution of the all patients.

\begin{tabular}{|c|c|c|}
\hline & & All patients $(n=60)$ \\
\hline \multicolumn{2}{|l|}{$\begin{array}{l}\text { Age (years) } \\
\text { Mean } \pm \text { SD } \\
\text { Range }\end{array}$} & $\begin{array}{c}3.96 \pm 2.71 \\
0.4-6\end{array}$ \\
\hline \multirow{2}{*}{ Sex } & Female & $28(46.7 \%)$ \\
\hline & Male & $32(53.3 \%)$ \\
\hline \multicolumn{2}{|l|}{$\begin{array}{l}\text { Weight }(\mathrm{kg}) \\
\text { Mean } \pm \text { SD }\end{array}$} & $12.86 \pm 5.79$ \\
\hline \multirow{2}{*}{ Residency } & Rural & $36(60 \%)$ \\
\hline & Urban & $24(40 \%)$ \\
\hline \multicolumn{2}{|c|}{ Consanguinity of parents } & $26(43.3 \%)$ \\
\hline
\end{tabular}

Table (1) shows that age of the study population ranged from $0.4-6$ years. Weight (mean \pm SD) was $(12.86 \pm$ $5.79) \mathrm{kg}$ and $46.7 \%$ of them were females. $43.3 \%$ of the patients had consanguinity of parents.

Table (2): Patient characteristics between convulsion and non- convulsion.

\begin{tabular}{|c|c|c|c|c|c|}
\hline & & $\begin{array}{c}\text { Convulsion } \\
(\mathrm{n}=11)\end{array}$ & $\begin{array}{c}\text { Non-convulsion } \\
(\mathrm{n}=49)\end{array}$ & $t / x^{2}$ & $\mathbf{P}$ \\
\hline \multicolumn{2}{|c|}{$\begin{array}{l}\text { Age (years) } \\
\text { Mean } \pm \text { SD }\end{array}$} & $4.11 \pm 2.83$ & $3.52 \pm 2.76$ & .638 & .526 \\
\hline \multirow{2}{*}{ Sex } & Female & $4(36.4 \%)$ & $24(49 \%)$ & \multirow{2}{*}{.575} & \multirow{2}{*}{.449} \\
\hline & Male & $7(63.6 \%)$ & $25(51 \%)$ & & \\
\hline \multicolumn{2}{|c|}{$\begin{array}{l}\text { Weight }(\mathrm{kg}) \\
\text { Mean } \pm \text { SD }\end{array}$} & $11.47 \pm 6.05$ & $14.38 \pm 5.52$ & 1.55 & .126 \\
\hline \multicolumn{2}{|c|}{ Consanguinity of parents } & $5(45.5 \%)$ & $21(42.9 \%)$ & .025 & .875 \\
\hline
\end{tabular}

This table shows that demographic data were comparable in both convulsion and non-convulsion patients. There was no significant between two groups regarding age, sex , weight and sonsanguinity.

Table (3): History and clinical characteristics among the studied patients according to convulsion.

\begin{tabular}{|c|c|c|c|c|c|c|}
\hline & & \multicolumn{2}{|c|}{$\begin{array}{c}\text { Convulsion } \\
(\mathbf{n}=11)\end{array}$} & \multicolumn{2}{|c|}{ Non-convulsion $(n=49)$} & \multirow[t]{2}{*}{$\mathbf{P}$} \\
\hline & & $\mathbf{N}$ & $\%$ & $\mathbf{N}$ & $\%$ & \\
\hline \multirow{3}{*}{ Fever } & No fever & 2 & 18.2 & 17 & 34.7 & \multirow{3}{*}{.014} \\
\hline & Mild fever & 3 & 27.3 & 25 & 51 & \\
\hline & High fever & 6 & 54.5 & 7 & 14.3 & \\
\hline \multirow{2}{*}{$\begin{array}{l}\text { Gastroenteritis } \\
\text { duration }\end{array}$} & $<5$ days & 4 & 36.4 & 33 & 67.3 & \multirow{2}{*}{.056} \\
\hline & $>5$ days & 7 & 63.6 & 16 & 32.7 & \\
\hline \multirow{2}{*}{ Vomiting frequency } & $<3$ times per day & 5 & 45.5 & 39 & 79.6 & \multirow{2}{*}{.021} \\
\hline & $>3$ times per day & 6 & 54.5 & 10 & 20.4 & \\
\hline \multirow{2}{*}{ Vomiting duration } & $<2$ days & 3 & 27.3 & 25 & 51 & \multirow{2}{*}{.154} \\
\hline & $>2$ days & 8 & 72.7 & 24 & 49 & \\
\hline \multirow{2}{*}{ Diarrhea frequency } & $<3$ times per day & 6 & 54.5 & 20 & 40.8 & \multirow{2}{*}{.406} \\
\hline & $>3$ times per day & 5 & 45.5 & 29 & 59.2 & \\
\hline \multirow{2}{*}{ Diarrhea duration } & $<3$ days & 4 & 36.4 & 23 & 46.9 & \multirow{2}{*}{.524} \\
\hline & $>3$ days & 7 & 63.6 & 26 & 53.1 & \\
\hline \multicolumn{2}{|l|}{ Hypoglycemia } & 3 & 27.3 & 9 & 18.4 & .559 \\
\hline
\end{tabular}

This table shows that high grade fever and vomiting more than 3 times per day were significantly more frequent in patients with convulsion compared to non-convulsion patients. 
Table (4): Electrolytes imbalance frequencies among the studied patients according to convulsion.

\begin{tabular}{|l|c|c|c|c|c|c||}
\hline \multirow{2}{*}{} & \multicolumn{2}{|c|}{$\begin{array}{c}\text { Convulsion } \\
(\mathbf{n = 1 1})\end{array}$} & \multicolumn{2}{c|}{ Non-convulsion (n=49) } & \multirow{2}{*}{$\mathbf{t} \square^{\mathbf{2}}$} & \multirow{2}{*}{$\mathbf{P}$} \\
\cline { 2 - 5 } & $\mathrm{N}$ & $\%$ & $\mathrm{~N}$ & $\%$ & & \\
\hline Hypokalemia & 1 & 9.1 & 1 & 2 & 1.39 & .239 \\
\hline Hyperkalemia & 5 & 45.5 & 7 & 14.3 & $\mathbf{5 . 4 6}$ & $\mathbf{. 0 1 9}$ \\
\hline Hyponatremia & 7 & 63.6 & 9 & 18.4 & $\mathbf{9 . 4 1}$ & $\mathbf{. 0 0 2}$ \\
\hline Hypernatremia & 2 & 18.2 & 4 & 8.2 & 1.02 & .319 \\
\hline Acidosis & 7 & 63.6 & 16 & 32.7 & 3.65 & .056 \\
\hline Alkalosis & 3 & 27.3 & 5 & 10.2 & 2.27 & .132 \\
\hline
\end{tabular}

This table shows that hyperkalemia and hyponatremia were significantly more frequent in patients with convulsion compared to non-convulsion patients.

Table (5): Laboratory parameters of the studied patients according to convulsion.

\begin{tabular}{|l|l|l|l|l||}
\hline & $\begin{array}{l}\text { Convulsion } \\
(\mathbf{n = 1 1})\end{array}$ & $\begin{array}{l}\text { Non-convulsion } \\
(\mathbf{n = 4 9 )}\end{array}$ & $\mathbf{t}$ & $\mathbf{P}$ \\
\hline $\begin{array}{l}\text { Hemoglobin }(\mathrm{g} / \mathrm{dl}) \\
\text { Mean } \pm \text { SD }\end{array}$ & $11.55 \pm 1.64$ & $12.18 \pm 1.43$ & 1.29 & .204 \\
\hline $\begin{array}{l}\text { TLC }\left(10^{3} / \mu \mathrm{L}\right) \\
\text { Mean } \pm \text { SD }\end{array}$ & $8.12 \pm 1.32$ & $6.87 \pm 1.02$ & 1.28 & .203 \\
\hline $\begin{array}{l}\text { PLT }\left(10^{3} / \mu \mathrm{L}\right) \\
\text { Mean } \pm \text { SD }\end{array}$ & $243.44 \pm 35.92$ & $268.18 \pm 37.87$ & 1.97 & .053 \\
\hline $\begin{array}{l}\text { RBS }(\mathrm{mg} / \mathrm{dl}) \\
\text { Mean } \pm \text { SD }\end{array}$ & $125.57 \pm 16.84$ & $116.14 \pm 19.61$ & 1.48 & .146 \\
\hline $\begin{array}{l}\text { Serum Creatinine }(\mathrm{mg} / \mathrm{dl}) \\
\text { Mean } \pm \text { SD }\end{array}$ & $0.654 \pm 0.154$ & $0.712 \pm 0.163$ & 1.08 & .286 \\
\hline $\begin{array}{l}\text { BUN }(\mathrm{mg} / \mathrm{dl}) \\
\text { Mean } \pm \text { SD }\end{array}$ & $25.11 \pm 3.27$ & $17.32 \pm 3.64$ & $\mathbf{3 . 7 8}$ & $\mathbf{. 0 0 0 4}$ \\
\hline $\begin{array}{l}\text { AST }(\mathrm{U} / \mathrm{L}) \\
\text { Mean } \pm \text { SD }\end{array}$ & $31.65 \pm 3.56$ & $33.38 \pm 4.60$ & .504 & .616 \\
\hline $\begin{array}{l}\text { ALT }(\mathrm{U} / \mathrm{L}) \\
\text { Mean } \pm \text { SD }\end{array}$ & $30.09 \pm 1.01$ & $28.36 \pm 4.11$ & .559 & .578 \\
\hline $\begin{array}{l}\text { CRP }(\mathrm{U} / \mathrm{L}) \\
\text { Mean } \pm \text { SD }\end{array}$ & $27.43 \pm 4.83$ & $18.76 \pm 4.29$ & $\mathbf{2 . 8 2}$ & $\mathbf{. 0 0 7}$ \\
\hline
\end{tabular}

This table shows that BUN and CRP were significantly higher in patients with convulsion compared to nonconvulsion patients.

Table (6): Electrolytes parameters of the studied patients according to convulsion.

\begin{tabular}{|l|c|c|c|c|}
\hline & $\begin{array}{c}\text { Convulsion } \\
(\mathbf{n = 1 1})\end{array}$ & Non-convulsion $(\mathbf{n = 4 9 )}$ & $\mathbf{t}$ & $\mathbf{p}$ \\
\hline $\begin{array}{l}\text { Calcium (mg/dl) } \\
\text { Mean } \pm \text { SD }\end{array}$ & $7.64 \pm 1.43$ & $8.18 \pm 1.05$ & 1.44 & .156 \\
\hline $\begin{array}{l}\text { Potassium (mmol/L) } \\
\text { Mean } \pm \text { SD }\end{array}$ & $4.12 \pm 0.802$ & $3.42 \pm 0.05$ & $\mathbf{2 . 1 1}$ & $\mathbf{. 0 4 0}$ \\
\hline $\begin{array}{l}\text { Sodium (mmol/L) } \\
\text { Mean } \pm \text { SD }\end{array}$ & $131.18 \pm 9.54$ & $136.28 \pm 6.33$ & $\mathbf{2 . 1 9}$ & $\mathbf{. 0 3 3}$ \\
\hline $\begin{array}{l}\text { PH } \\
\text { Mean } \pm \text { SD }\end{array}$ & $7.34 \pm 0.529$ & $7.43 \pm 0.383$ & .655 & .515 \\
\hline
\end{tabular}

This table shows that sodium was significantly lower in patients with convulsion compared to non-convulsion patients. Meanwhile, potassium was significantly higher in patients with convulsion compared to non-convulsion patients. 
Table (7): Multivariate logistic regression analysis to determine predictors of the likelihood of convulsion.

\begin{tabular}{|l|c|c|c|c|c|c|}
\hline & \multirow{2}{*}{$\mathbf{B}$} & \multirow{2}{*}{ S.E. } & \multirow{2}{*}{ Sig. } & \multirow{2}{*}{ OR } & \multicolumn{2}{|c|}{$\mathbf{9 5 \%}$ CI for OR } \\
\cline { 5 - 7 } & & & & & Lower & Upper \\
\hline High grade fever & .130 & .177 & $\mathbf{. 0 0 3}$ & 1.138 & .805 & 1.609 \\
\hline Gastroenteritis for $>\mathbf{5}$ days & 1.403 & .932 & $\mathbf{. 0 0 2}$ & 0.246 & .040 & 1.529 \\
\hline Vomiting >3 times per day & 1.406 & 1.691 & $\mathbf{. 0 4 6}$ & 4.080 & .148 & 12.187 \\
\hline Vomiting for >2 days & .939 & 1.171 & .423 & 2.557 & .258 & 25.362 \\
\hline Diarrhea $>\mathbf{3}$ times per day & 2.797 & 1.720 & .104 & 16.403 & .563 & 47.912 \\
\hline RBS & .023 & .001 & .493 & 1.024 & .536 & 1.954 \\
\hline Serum Creatinine & .547 & .005 & .459 & .798 & .439 & 1.451 \\
\hline BUN & 5.564 & .039 & $\mathbf{. 0 3 8}$ & 1.911 & 1.844 & 17.984 \\
\hline CRP & 3.050 & .064 & .057 & 1.488 & .330 & 25.720 \\
\hline Calcium & 1.533 & .011 & .121 & 1.919 & 0.873 & 7.967 \\
\hline Potassium & 2.319 & .049 & $\mathbf{. 0 1 1}$ & 1.916 & 1.160 & 13.266 \\
\hline Sodium & 35.796 & .500 & $\mathbf{. 0 0 1}$ & 22.402 & 3.946 & 34.734 \\
\hline PH & 1.082 & .005 & .311 & 1.064 & 1.026 & 1.103 \\
\hline
\end{tabular}

This table showed that high grade fever, gastroenteritis more than 5 days, vomiting more than 3 times per day, increase BUN, hyperkalemia and hyponatremia found to be significant predictors of convulsion.

\section{DISCUSSION}

Analysis of our findings revealed that the age of the study population ranged from $0.4-6$ years. Weight (mean \pm SD) was $(12.86 \pm 5.79) \mathrm{kg}$ and $46.7 \%$ of them were females. $43.3 \%$ of the patients had consanguinity of parents.

In agreement with our findings, the study of Khosroshahi et al. ${ }^{(11)}$ in which over a 2-year period, a total of 25 patients, 11 males and 14 females, aged 3 to 48 months (median age 14 months), were admitted to the hospital with presenting feature of new-onset afebrile seizures associated with mild diarrhea. Approximately half $(46.7 \%)$ of the patients were between 12 and 24 months old.

Similar to our findings, the study of Vafaei $\boldsymbol{e t}$ al. (10) was carried out on a total of 100 children admitted to Tabriz Children's Hospital during the period from 2001 to 2016, with diagnosis of gastroenteritis associated with seizure. The patients consisted of 44 boys (52.4\%), and 40 girls (47.6\%). The mean age of study was $9.31 \pm 7.13$ years. The mean weight was $11.64 \pm 5.33 \mathrm{~kg}$.

Although the exact role of genetic susceptibility in mechanism of benign convulsion with mild gastroenteritis is not well understood, $43.4 \%$ of our patients had positive family consanguinity. Only a few investigators like Verrotti et al. (5) had demonstrated the positive family history in benign convulsion with mild gastroenteritis. It seems that further studied are needed to determine the role of genetic susceptibility in this issue.

In the present study, majority of cases $46.7 \%$ had mild fever. $61.7 \%$ of cases had gastroenteritis $<5$ days, vomiting frequency was $<3$ times per day in $73 \%$, and $20 \%$ of cases had hypoglycemia. As regard to laboratory findings (mean $\pm \mathrm{SD}$ ), hemoglobin was $(13.44 \pm 1.29) \mathrm{g} / \mathrm{dl} \mathrm{TLC}$ was $(7.69 \pm 2.34)\left(\mathrm{x} 10^{3} / \mathrm{ul}\right)$, PLT was (258.17 \pm 45.15$)\left(\mathrm{x} 10^{3} / \mathrm{ul}\right)$, RBS was $97.35 \pm$ $12.78 \mathrm{mg} / \mathrm{dl}$, Creatinine was $0.563 \pm 0.173 \mathrm{mg} / \mathrm{dl}$, BUN was $23.17 \pm 6.84 \mathrm{mg} / \mathrm{dl}$, CRP was $25.45 \pm 6.29$ $\mathrm{mg} /$

In agreement with our findings, Narchi ${ }^{(12)}$ stated that all 14 children in his study had normal full blood count, blood film, serum urea, creatinine, electrolytes, and glucose, calcium and magnesium levels.

According to the results in the study of Yousefichaijan et al. ${ }^{(13)}$, the majority of the cases had normal WBC, while 44 patients had leukocytosis and 24 were febrile. Therefore, it seems logical to evaluate WBC in febrile gastroenteritis patients. The topic of evaluation of initial tests for moderate to severe diarrhea has been pointed out in previous studies. However, leukocytosis may occur following stress. In addition, the study of white blood cells has no validity in proving or disproving diarrhea and vomiting, but it is usually used to determine the underlying causes of fever, like other children's' infectious diseases.

In the current study, we demonstrated that mean serum calcium was $5.55 \pm 0.614 \mathrm{mg} / \mathrm{dL}$, mean potassium was $4.72 \pm 0.632 \mathrm{mmol} / \mathrm{L}$, mean sodium was $135.67 \pm 5.82 \mathrm{mmol} / \mathrm{L}$ and mean $\mathrm{PH}$ was 7.36 \pm 0.694 , and we found that acidosis and hyponatremia were the most frequent imbalance among the patients.

Our results was similar to the study of Yilmaz et al. ${ }^{(14)}$ and Hayajneh et al. ${ }^{(15)}$ who found that serum urea, creatinine, sodium, potassium, and glucose were useful independently in children presenting with gastroenteritis, and serum urea was found to be the best among all. In comparison to the results in the study of 
Yousefichaijan et al. ${ }^{(13)}$, where the majority of the patients had normal serum sodium,

In agreement with our findings, the Dastidar and Konar (16) study, 170 children (85\%) had Normokalemia and 30 cases (15\%) had Hypokalemia and none of the cases had hyperkalemia. Six cases of hyponatremia had associated hypokalemia. In this study, 173 children (86.5\%) had Normochloremia, 25 (12.5\%) had Hypochloremia and 2 (1\%) had Hyperchloremia. Out of the 25 cases of Hypochloremia, 8 had associated Hyponatremia and 21 children had associated Hypokalemia as well. Purohit and Jyotsna ${ }^{(\mathbf{1 7})}$ noted Hypochloremia in 59\% of his cases and he attributed the higher incidence to associated vomiting.

In the current study, we found that 11(18\%) of participants developed convulsions, and on comparison, we found that there was non-statistical significant differences between convulsion and nonconvulsion groups as regard each of age, sex, body weight and consanguinity.

In studies of Kikuchi et al. ${ }^{(18)}$ and Weng $\boldsymbol{e t}$ al. ${ }^{(19)}$, the prevalence of seizure and gastroenteritis is more common in females than males. The prevalence of males/females is 1/1.5-1.8. Furthermore, in contrary to our findings, the study of Vafaei $\boldsymbol{e t}$ al. ${ }^{(\mathbf{1 0})}$ reported that the ratio was in favor of male and males / females ratio was $52.4 \% / 47.6 \%$. Family history in these people is usually negative.

The most important complication of gastroenteritis in children is seizure, which is one of the causes of fever, electrolyte disturbances, meningitis and sometimes toxins. Electrolyte disturbances such as hyponatremia, hypernatremia, hypoglycemia and hypocalcemia are the major cause of seizures in these children ${ }^{(7)}$.

In addition to above findings, the current study revealed that high grade fever and vomiting more than 3 times per day were significantly more frequent in patients with convulsion compared to non-convulsion patients. Although fever is common during viral gastroenteritis and therefore can occur during convulsion with gastroenteritis, the body temperature is $\angle 38^{\circ} \mathrm{C}$ during seizure episodes in convulsion with gastroenteritis. A history of prolonged fever with deteriorating neurologic signs and symptoms should raise the possibility of a more severe and progressive CNS infection associated with viral gastroenteritis.

In agreement with our findings, Dastidar and Konar ${ }^{(16)}$ stated that 54\% (108) cases had fever and Srivastava et al. ${ }^{(20)}$ reported fever in $40 \%$ cases. $56.4 \%$ (88/143) with iso-natremia and $54.5 \%$ (20/44) with Hyponatremia had fever as a symptom.

Our results are supported by the study of Heydarian et al. ${ }^{(21)}$ who reported that the 165 children $47.3 \%$ were female. Vomiting was $2.7 \pm 2.6$ and $3.9 \pm 1.9$ times in febrile and afebrile group. Duration of diarrhea was $1.8 \pm 1.8$ days and $2.1 \pm 1.3$ days in febrile and afebrile groups $(\mathrm{p}=0.014) .36 \%$ in febrile group and $6.4 \%$ in afebrile group experienced seizure within the first $24 \mathrm{~h}$ of gastroenteritis $(\mathrm{P}<0.001)$. Seizure in $99.1 \%$ in febrile and $93.6 \%$ in afebrile group was generalized $(\mathrm{P}>0.05)$. Seizure was more than $5 \mathrm{~min}$ in $51.4 \%$ in febrile and $57.4 \%$ in afebrile groups $(\mathrm{P}>0.05)$. Drowsiness after seizure was seen in $72.9 \%$ and $60 \%$ in febrile and afebrile group respectively $(\mathrm{P}>0.05)$. The serum level of sodium was 137.6 \pm 3.98 $\mathrm{mEq} / \mathrm{L}$ and $138.5 \pm 3.78 \mathrm{mEq} / \mathrm{L}$ in febrile and afebrile groups ( $\mathrm{P}>0.05$ ). $26.3 \%$ in febrile group and $8.5 \%$ in afebrile group had hyponatremia $(\mathrm{P}=0.012)$. There was no difference in seizure duration between hyponatremic patients and others $(\mathrm{P}>0.05)$.

Our findings can be explained by that electrolyte abnormalities are commonly encountered in clinical daily practice, and their diagnosis relies on routine laboratory findings. Electrolyte disturbances may affect the brain among many other organs and tissues and need to be promptly recognized as they may lead to severe and life-threatening complications when overlooked or not appropriately treated. The neurological manifestations reflect the severity of acute neuronal derangement and therefore require emergency treatment. Acute and/or severe electrolyte imbalances can manifest with rapidly progressive neurologic symptoms or seizures, which may be the sole presenting symptom. Seizures are more frequently observed in patients with sodium disorders (especially hyponatremia), hypocalcemia, and hypomagnesaemia (22).

Furthermore, as regard laboratory differences between convulsion and non-convulsion groups, we found that BUN and CRP were significantly higher in patients with convulsion compared to non-convulsion patients, moreover; we found that sodium was significantly lower in patients with convulsion compared to non-convulsion patients. Meanwhile, potassium was significantly higher in patients with convulsion compared to non-convulsion patients.

In contrary to our study, the study of Afsharkhas and Tavasoli ${ }^{(23)}$ revealed that there were no abnormalities in serum magnesium, Blood Urea Nitrogen (BUN), and creatinine levels.

Finally, Multivariate logistic regression analysis to determine predictors of the likelihood of convulsion was done, and reached to that high grade fever, gastroenteritis for $>5$ days, vomiting $>3$ times per day, BUN, potassium and sodium found to be significant predictors of convulsion.

In a harmony with our findings, the study done by Vafaei $\boldsymbol{e t}$ al. ${ }^{(10)}$ who used the regression logistic statistical test, among the examined biomarkers and electrolytes, only BUN has proven to be a strong predictor of the likelihood of seizure $(\mathrm{p}=0.02$, Odds Ratio: $1.31, \mathrm{Z}$ value: 1.31 ). Although $\mathrm{PH}$ had a nonspecific p-value, but it had a strong association with seizure (P-value: 0.19, Odds Ratio: 0.85, Z-value: 2.29). 


\section{CONCLUSION}

According to the results of this study, electrolyte impairment is fairly common in children with acute gastroenteritis.

- Acidosis and hyponatremia were the most frequent imbalance among the patients.

- Hyperkalemia and hyponatremia were significantly more frequent in patients with convulsion compared to non-convulsion patients.

- High grade fever, gastroenteritis for > 5 days, vomiting $>3$ times per day, blood urea nitrogen, potassium and sodium found to be significant predictors of convulsion.

- Education about the management of children with seizure can be an important factor in this regard.

\section{REFERENCES}

1. Kianifar H, Ahanchian $H$, Grover $Z$ et al. (2014): Synbiotic in the management of infantile colic: A randomised controlled trial. Journal of Paediatrics and Child Health, 50(10):801-5.

2. Cusmai R, Jocic-Jakubi B, Cantonetti L et al. (2010): Convulsions associated with gastroenteritis in the spectrum of benign focal epilepsies in infancy: 30 cases including four cases with ictal EEG recording. Epileptic Disord., 12(4):255-61.

3. Kang B, Kwon Y (2014): Benign convulsion with mild gastroenteritis. Korean J Pediatr., 57(7):304-9.

4. Motoyama M, Ichiyama T, Matsushige T et al. (2009): Clinical characteristics of benign convulsions with rotavirus gastroenteritis. J Child Neurol., 24(5):557-61.

5. Verrotti A, Nanni G, Agostinelli S et al. (2011): Benign convulsions associated with mild gastroenteritis: a multicenter clinical study. Epilepsy Res., 93(2-3):107114.

6. Maruyama K, Okumura A, Sofue A et al. (2017): Ictal EEG in patients with convulsions with mild gastroenteritis. Brain Dev., 29(1):43-6.

7. Li T, Hong S, Peng $X$ et al. (2014): Benign infantile convulsions associated with mild gastroenteritis: an electroclinical study of 34 patients. Seizure, 23(1):16-9.

8. Wang Y, Zhou $Z$ (2013): Clinical features of benign convulsions with mild gastroenteritis in Chinese infants. World J Pediatr., 9(1):73-5.

9. Ueda H, Tajiri H, Kimura $S$ et al. (2015): Clinical characteristics of seizures associated withviral gastroenteritis in children. Epilepsy Res., 109:146-54.

10. Vafaei I, Rezazadehsaatlou M, Abdinia B et al. (2017): Study of the Determinant Factors in Seizure Following
Gastroenteritis in Children Admitted in Tabriz Children's Hospital during 2001 to 2016. Int J Pediatr., 5(12): 643946.

11. Khosroshahi N, Rahbarimanesh A, Boroujeni F et al. (2018): Afebrile Benign Convulsion Associated With Mild Gastroenteritis: A Cohort Study in a Tertiary Children Hospital. Child Neurology Open, 5: 498-503.

12. Narchi H (2004): Benign afebrile cluster convulsions with gastroenteritis: an observational study. BMC Pediatr., 4: 2-6.

13. Yousefichaijan P, Dorreh F, Ziaei E et al. (2016): Distribution of Abnormal Laboratory Tests in Patients with Dehydration Due to Gastroenteritis: A Medical Audit Study, J Compr Ped., 7(4):387-93.

14. Yilmaz K, Karabocuoglu M, Citak A et al. (2002): Evaluation of laboratory tests in dehydrated children with acute gastroenteritis. J Paediatr Child Health, 38(3): 2268.

15. Hayajneh W, Jdaitawi H, Al Shurman A et al. (2010): Comparison of clinical associations and laboratory abnormalities in children with moderate and severe dehydration. J Pediatr Gastroenterol Nutr., 50(3): 290 -4.

16. Dastidar R, Konar N (2017): A Study of Electrolyte Disturbances in a Child Presenting with Acute Gastroenteritis, with Special Emphasis on Hyponatremic Dehydration-A Hospital based Cross-Sectional Study. Pediatr Ther., 7: 322-26.

17.Purohit K, Jyotsna P (1971): Electrolyte disturbances in Acute Diarrhea. Indian J Pediatr., 38: 393-395.

18. Kikuchi K, Hamano S, Higurashi N et al. (2015): Difficulty of Early Diagnosis and Requirement of LongTerm Follow-Up in Benign Infantile Seizures. Pediatr Neurol., 53(2):157-62.

19. Weng W, Hirose S, Lee W (2010): Benign convulsions with mild gastroenteritis: is it associated with sodium channel gene SCN1A mutation? J Child Neurol., 25(12):1521- 24.

20.Srivastava A, Bhatnagar J, Prasad B et al. (1973): A clinical and aetiological study of diarrhoea in hospitalized children at Lucknow. Indian J Med Res., 61: 596-602.

21.Heydarian F, Bakhtiari E, Badzaee S et al. (2019): Gastroenteritis Related Seizure with or without Fever: Comparison Clinical Features and Serum Sodium Level. Iranian Journal of Child Neurology, 13(2): 47-52.

22. Nardone R, Brigo F, Trinka E (2016). Acute Symptomatic Seizures Caused by Electrolyte Disturbances. Journal of Clinical Neurology (Seoul, Korea), 12(1): 21-33.

23. Afsharkhas L, Tavasoli A (2014). Renal function in children with febrile convulsions. Iranian Journal of Child Neurology, 8(4): 57-61. 